\title{
Comprehensive Study of the Sand Spit Evolution at Tidal Inlets in the Central Coast of Vietnam
}

\author{
Nguyen Quang Duc Anh ${ }^{1}{ }^{(}$, , Hitoshi Tanaka ${ }^{2}{ }^{\circledR}$, Ho Sy Tam ${ }^{3, *}$, Nguyen Xuan Tinh ${ }^{2}{ }^{\circledR}$, \\ Tran Thanh Tung ${ }^{3}$ and Nguyen Trung Viet ${ }^{3}$ (i) \\ 1 Vietnam-Netherlands Center for Water and Environment, Thuyloi University, 175 Tay Son, Dong Da, \\ Hanoi 10000, Vietnam; ducanh.cte@gmail.com \\ 2 Department of Civil Engineering, Tohoku University, Sendai 6-6-06, Japan; \\ hitoshi.tanaka.b7@tohoku.ac.jp (H.T.); nguyen.xuan.tinh.c5@tohoku.ac.jp (N.X.T.) \\ 3 Faculty of Civil Engineering, Thuyloi University, 175 Tay Son, Dong Da, Hanoi 10000, Vietnam; \\ T.T.Tung@tlu.edu.vn (T.T.T.); nguyentrungviet@tlu.edu.vn (N.T.V.) \\ * Correspondence: tamhs.cttl@tlu.edu.vn
}

Received: 6 August 2020; Accepted: 13 September 2020; Published: 18 September 2020

\begin{abstract}
Tidal inlets along the central coast of Vietnam are located in a microtidal, wave-dominated coastal environment. In addition, the Vietnam coast is highly influenced by the seasonal monsoon regime, which is characterized by large northeast waves from October to March and calm southeast waves from April to September every year. Consequently, the tidal inlet entrance morphologies often suffer from a dynamic seasonal evolution due to distinct differences in the direction of wave-induced longshore sediment transport (LST) between the two monsoon seasons. The migration or closure of tidal inlets causes a lot of problems for socio-economic development in the region since these are the main reasons leading to an increase in the risk of coastal flooding and the obstruction of navigation. This paper presents a comprehensive study of the morphological evolutions of natural tidal inlets on the central coast of Vietnam using long-term remote sensing data sets and by the Delft3D numerical model. Surprisingly, the estimated LST rates from the former method are in an order of magnitude agreement with the results from the latter one for all of the areas in this study. Based on the conservation equation for sand and comprehensive data collection, a new simple empirical formula for predicting the sand spit elongation rate as a function of the sand spit width is developed. Although the breaching of sand spit might happen during an extreme flood event at some tidal inlets, the growth rate of the spit before and after the breaching is almost unchanged. These findings are very useful information for supporting the local coastal authorities to find better management solutions in terms of sustainable development.
\end{abstract}

Keywords: tidal inlet; river mouth; sand spit elongation; longshore sediment transport; inlet migration; image analysis; central coast of Vietnam; Delft3D

\section{Introduction}

Sand spits are one of the most dynamic and complex geographical features in coastal bays, lagoons, and river mouths. The development and evolution of sand spits along the world's river mouths have long been a concern of scientists due to their ecological and economic importance [1]. The morphological changes in sand spits highly depend on the interactions between wave transformation, tidal exchange, and longshore sediment transport (LST), as well as river discharge. Allard et al. [2] have shown that wave-induced current processes were the most important factors in the morphological changes in sand spits. Besides this, the geological framework, sea-level rise, sediment availability, and human impacts also play important roles in illustrating the complexity of sand spit morphological evolution $[3,4]$. 
Aubrey and Gaines [5] described two general mechanisms for sand spit development. The first mechanism is through accretion by LST, while the second mechanism is associated with the migration of a tidal inlet. However, a detailed understanding of wave - current interactions and driving force mechanisms of sand spit morphological changes in the tidal inlet region is still a challenge due to limitations of measurement data sets [6,7]. Traditional in situ measurements can provide locally a direct estimation of many parameter, but cannot fully describe the complex physical processes. Sophisticated numerical models that predict the hydrodynamics and sediment transport of the nearshore environments are reaching a level of complexity and numerical efficiency, but they require extensive data sets, including accurate and up-to-date bathymetric information [8-11]. As an alternative, remote sensing techniques such as video-camera systems [12], Light Detection and Ranging (liDAR) [13], X-band radar [14,15], and satellite imageries [16,17] can provide synoptic coverage over large areas with a wide range of temporal and spatial resolutions. Among these studies, Honegger et al. (2020) [15] successfully extended the $c B a t h y$ depth estimate algorithm to obtain the high-resolution bathymetry of a complex tidal inlet environment based on the time series of X-band radar image, while Rogowski et al. (2018) [14] directly used X-band observations to accurately map the morphological changes in shallow ebb tidal deltas at the New River Inlet, North Carolina. Although most remote-sensing technologies are low-cost, only satellite images are free, available in the long-term, and cover most places on earth. Therefore, exploiting applications of satellite images for areas which have limited field measurement data should be the first option.

The coastal estuaries in Vietnam can be roughly classified into three large regions of land i.e., (i) a large delta with a gently sloping beach, which is the Mekong Delta; (ii) Red River Delta; and (iii) the central regions of Vietnam, with short and steeply sloping rivers originating from high mountains and flowing to the sea. By analyzing the Landsat images of 1973 and 2014, Besset et al. [18] indicated that the recent shoreline retreat on the south coast of the Mekong River mouth was highly likely related to a number of human activities such as upstream river dams, sand mining, and groundwater extraction in the region (i). Hung and Larson [19] conducted a detailed analysis of the adjacent coasts to the region of the (ii) Red River Delta. In region (iii), Duy et al. [20] studied the elongation of sand spits in the Cua Lo River Mouth, located in Quang Nam province in the center of Vietnam. They reported that the sand spit elongation rate in the Cua Lo Inlet was constantly at a rate of $50 \mathrm{~m} / \mathrm{y}$ to the south over the past 30 years. In addition, using the long-term satellite data sets, Duc Anh et al. [16,17] analyzed the sand spit evolutions at various tidal inlets including the Ken Inlet, Phan Inlet, and Loc An Inlet along the central coast of Vietnam. They also indicated that the migration rates of a tidal inlet were dependent on several factors, such as the wave characteristics, river flow, and sediment supply from the adjacent beaches. In addition, the breaching of the sand spit often occurred during extreme river flooding.

In this study, a further analysis of the sand spit evolutions at the Ly Hoa tidal inlet in Quang Binh province and the An Du tidal inlet in Binh Dinh province will be conducted. Both tidal inlets are also located in the central coast of Vietnam. Hence, a comprehensive comparison will be made by compiling the results from all tidal inlets in the region (iii). Based on this, the mechanisms of the sand spit morphological evolutions of tidal inlets in the central coast of Vietnam are quantified. The obtained results from this study are very useful information for helping the local coastal authorities to find better management solutions for the sustainable development of tidal inlets and river estuaries in the central coast of Vietnam.

\section{Materials and Methods}

\subsection{Study Areas}

The central coast is situated from $18^{\circ} 45^{\prime}$ to $10^{\circ} 45^{\prime}$ north latitude and from $105^{\circ} 06^{\prime}$ to $109^{\circ} 28^{\prime}$ east longitude and consists of 18 provinces with more than $1000 \mathrm{~km}$ of coastline (Figure 1). The tidal inlets in this area are characterized by long sand spits at the river mouths. Some typical sand spits 
can be seen at tidal inlets such as the Ly Hoa Inlet (Quang Binh province), An Du Inlet (Binh Dinh province), An Hai and Le Thinh Inlet (Phu Yen province), Ken Inlet (Ha Tinh province), and Phan Inlet (Binh Thuan province). These tidal inlets remain in quite natural conditions, and their evolutions are usually governed by natural processes. Although the study areas are six tidal inlets located along the central coast of Vietnam, this study will present a detailed analysis of the sand spit evolutions at Ly Hoa Inlet in Quang Binh Province and An Du Inlet in Binh Dinh province. Other tidal inlets can be found in studies by authors in $[16,17,20]$.

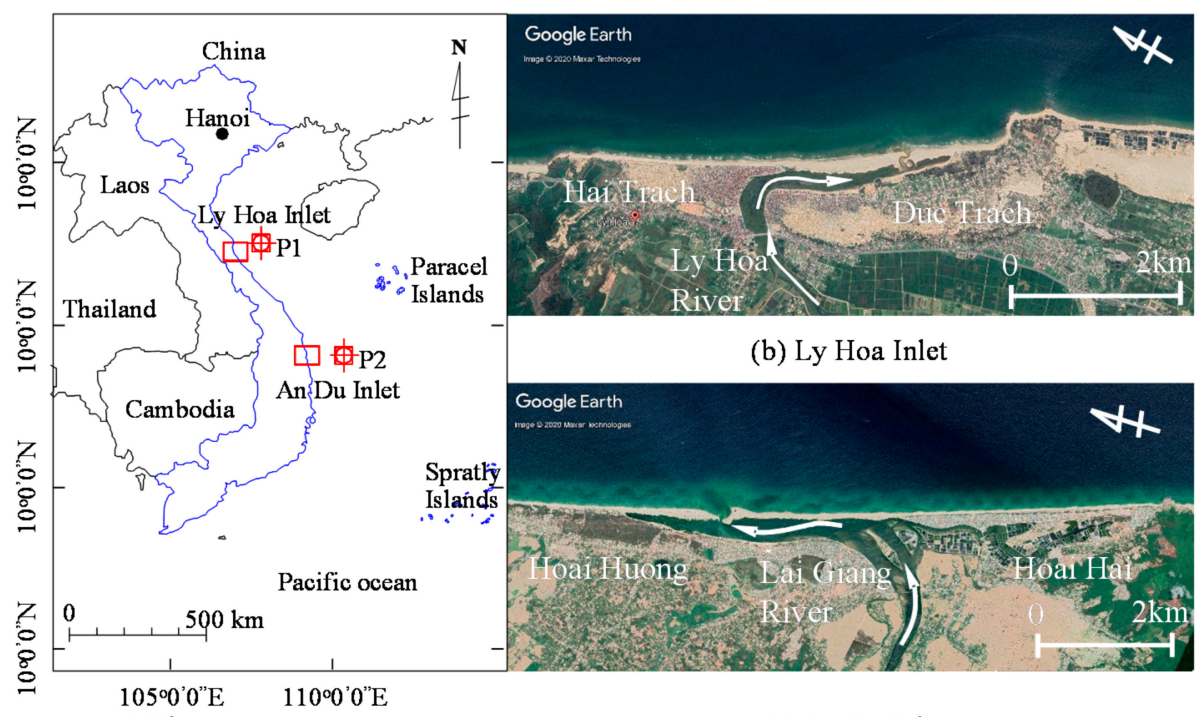
(a) Vietnam map
(c) An Du Inlet

Figure 1. (a) Location of Ly Hoa Inlet and An Du Inlet on the Vietnam map, (b) Ly Hoa Inlet morphology, and (c) An Du Inlet morphology.

Ly Hoa River originates from the east of the Truong Son mountain range and flows from the northwest to southeast direction. It is one of the smallest basins in the central coast of Vietnam with, a river basin of $177 \mathrm{~km}^{2}$ and a length of $25 \mathrm{~km}$. The most downstream end of the river before pouring into the East Sea tends to bend sharply to the south compared to the main direction of the river (Figure 1a,b).

An Du inlet is the mouth of Lai Giang River, which is located about $75 \mathrm{~km}$ north of Qui Nhon city, the center of Binh Dinh province (see Figure 1a). The Lai Giang river basin and the length of the main river are $1466 \mathrm{~km}^{2}$ and $85 \mathrm{~km}$, respectively. As shown in Figure 1c, the Lai Giang River changes its main flow direction at an angle of about $90^{\circ}$ to the north, after discharging into the sea. An Du estuary has two long sand spits at the river entrance. The estuary morphological changes are the main concerns in this area, because there is a fishing port inside the An Du river mouth.

\subsection{Data Collections}

To achieve the above objectives, the current study attempts to collect as full data sets as possible. The required data sets include satellite imageries for the shoreline detection, river discharge, water level, and wave information as well as bathymetry data.

In this study, the long-term satellite image data is firstly utilized to investigate the morphological evolution characteristics of the sand spits at two study cases in Ly Hoa Inlet and An Du Inlet in Vietnam. All the available satellite images were collected from free satellite imagery sources, such as from the U.S. Geological Survey-National Aeronautics and Space Administration (USGS-NASA), and Moderate Resolution Imaging Spectroradiometer (MODIS), as well as Google Earth Pro Software (Google, Digital Globe). A summary of the collected images for both study areas is shown in Table 1. The Landsat 4-5 and 7-8 images have a relatively resolution of $15 \div 30 \mathrm{~m} /$ pixel. However, the higher resolution images from the Google Earth ${ }^{\mathrm{TM}}$ are only $2.1 \mathrm{~m} /$ pixel. It is noted that the collected images must meet 
the quality requirements, such as a cloud cover that is less than $20 \%$, and should not be stretched or blurred. The detected shoreline positions from the satellite images are used for the estimation of sand spit area change in a similar method to that of $[21,22]$.

Table 1. A summary of the collected satellite images for the Ly Hoa and An Du study areas.

\begin{tabular}{cccc}
\hline Type of Images & Ly Hoa Inlet & An Du Inlet & Resolution \\
\hline Landsat $4,5,7,8$ & 116 images & 80 images & $15 \div 30 \mathrm{~m} /$ pixel \\
\hline Google Earth & 6 images & 5 images & $2.1 \mathrm{~m} /$ pixel \\
\hline
\end{tabular}

Figure 2(a1,b1) show the time series of the daily-average river discharge from the upstream of Ly Hoa River and Lai Giang River, respectively. In these figures, the discharge data were provided by the local river authority. It can be seen that the river discharge was low in the dry season lasting from December to May, whereas it was very high in the rainy season from June to November every year. The maximum of the daily-average discharges in Ly Hoa River and Lai Giang River can be up to 700 and $2500 \mathrm{~m}^{3} / \mathrm{s}$, respectively.

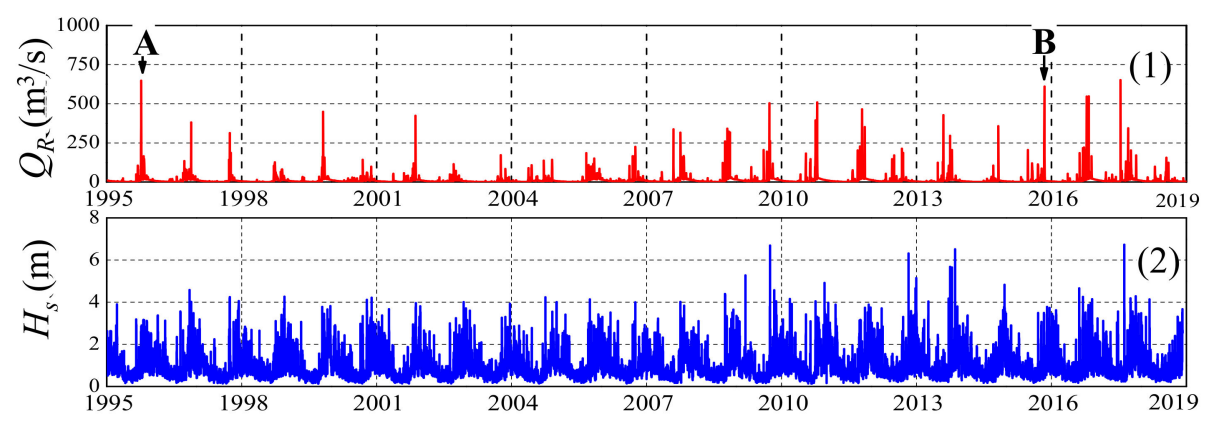

(a) Ly Hoa River: (1) Daily averaged discharge. (2) Offshore wave height from 1995 to 2019

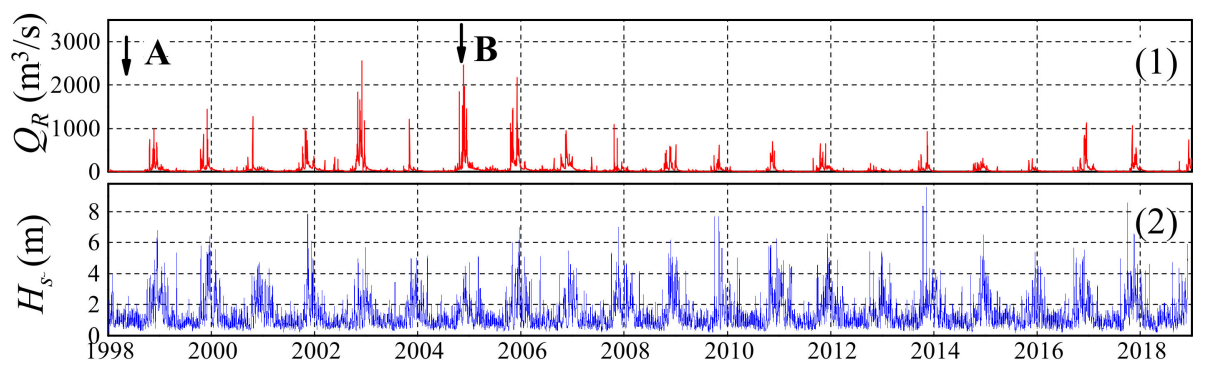

(b) Lach Giang River: (1) Daily averaged discharge. (2) Offshore wave height from 1998 to 2019

Figure 2. Hydrodynamic conditions at (a) Ly Hoa River and (b) Lach Giang River.

Figure 2(a2,b2) show the time series of the offshore significant wave heights from the simulating waves nearshore (SWAN) model for the East Vietnam Sea region that was developed and validated by Dien et al. [23]. The extracted wave stations for the Ly Hoa area and An Du area are denoted as P1 $\left(18^{\circ}, 107.5^{\circ}\right)$ and $\mathrm{P} 2\left(14.5^{\circ}, 110.5^{\circ}\right)$ in Figure 1. The P1 and P2 stations are located at about 110 and $150 \mathrm{~km}$ seaward from the inlets, respectively. The maximum wave height can reach up to $7.0 \mathrm{~m}$ for the Ly Hoa area and $9.0 \mathrm{~m}$ for the An Du area.

Figure 3 shows the daily-average energy mean parameters, including the energy mean wave height, energy mean wave period, and energy mean wave direction. Goda's equation [24] was used to calculate the energy mean waves from the hourly wave data from 1990 to 2019. As can be seen from this figure, the wave regime in these two areas are strongly affected by the monsoon season, in which high waves from the $\mathrm{NE}\left(45^{\circ}\right)$ direction dominates from October until March and relatively 
small waves from the SSW $\left(120^{\circ}\right)$ and SSW $\left(160^{\circ}\right)$ directions are present from April until September every year.

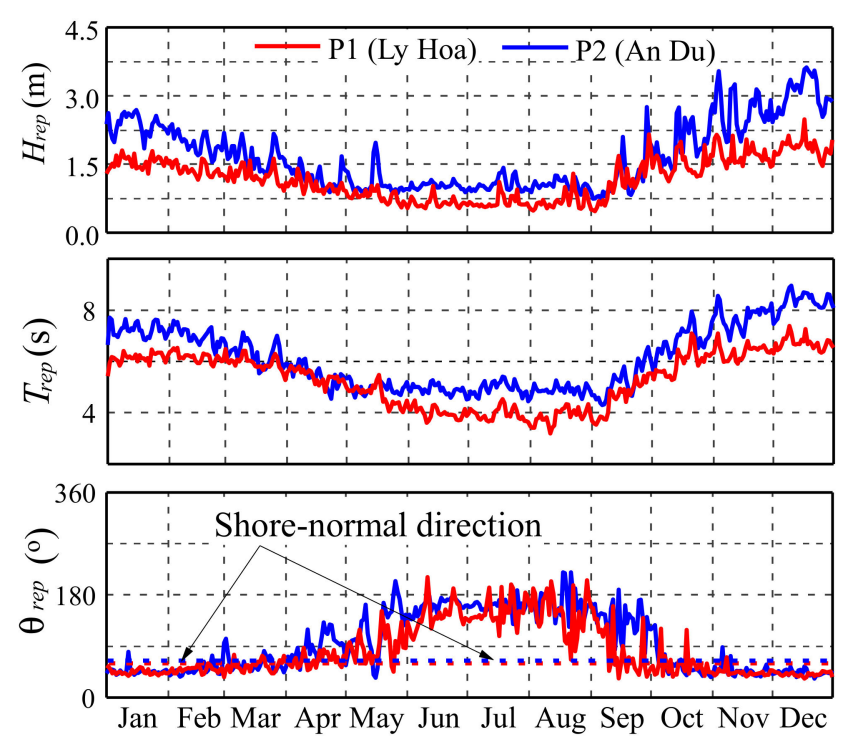

Figure 3. Daily-averaged wave energy from 1998-2019.

According to Tung [25], the tides along the central coast of Vietnam are a relatively small, complex regime, and the tidal range varies according to the region from 0.5 to $1.5 \mathrm{~m}$.

The bathymetry data for the numerical model were combined from several sources, including the measurement data from the previous projects by local government, the General Bathymetric Chart of the ocean data [26], and the Vietnam Bathymetry data.

\subsection{Image Rectification and Shoreline Extraction Methods}

Image rectification is a process of transforming information from one image into a common mapping system using geometric transformation [27-30]. In this study, the mapping method presented in Pradjoko and Tanaka [30] was utilized. This mapping method was reported to have a maximum error of up to $6 \mathrm{~m}$ in the rectification. This process is carried out by matching corresponding points from the mapping system with the same points of the image to be processed. Therefore, it is vital to choose a certain number of appropriate Ground Control Points (GCPs) which belong to the original images. GCPs have been chosen as permanent objects or stationary features e.g., road intersections, building corners, or sea walls, etc. Hence, detected shoreline positions, which are defined as a wet-dry line and extracted from the rectified satellite images in a direction along the beach, are used to analyze the shoreline changes and sand spit morphological changes for each tidal inlet.

\subsection{Longshore Sediment Transport Rates Estimation Method}

In this study, a simple model for an unrestricted sand spit elongation that is similar to the method developed by Tanaka et al. [31], Kraus [32], and Larson et al. [33] is utilized. The main assumptions in this model are the sand spit growth solely contributed by the gradients in LST $\left(Q_{x}\right)$; the sand spit width $\left(B_{S}\right)$ is maintained as a constant, and the spit contours move in parallel over the representative time scales. Figure 4 shows a definition sketch for sand spit elongation in a tidal inlet. In time interval $\Delta t$, the sand spit volume change $\Delta V$ equals the newly developed area of sand spit $(\Delta A)$ multiplied by the depth of active motion $D=D_{B}+D_{C}$, where $D_{B}$ is the berm height and $D_{C}$ is the depth of closure as seen in Figure 4a. 


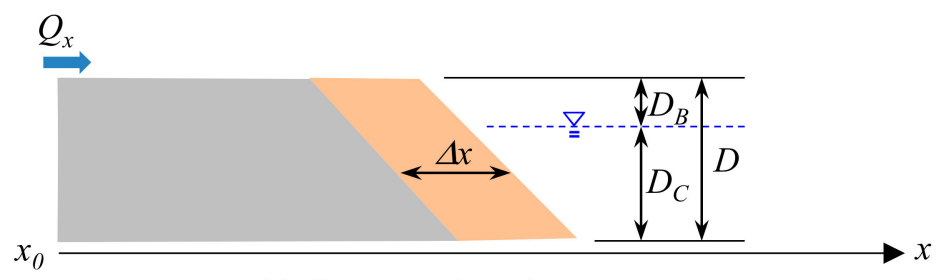

(a) Cross-section view

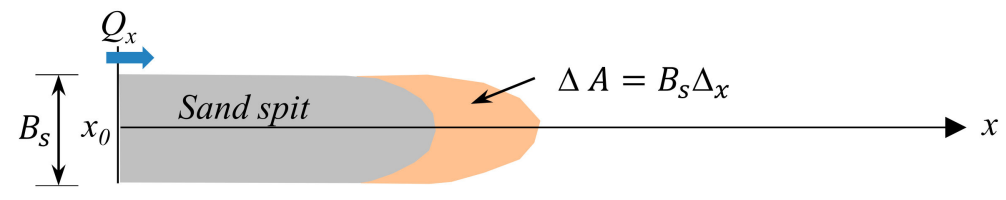

(b) Plan view

Figure 4. Definition sketch for sand spit elongation: (a) Cross-section view (b) Plan view.

We assume that the sand spit volume change is equal to the volume entering $\left(Q_{i n}\right)$ minus that leaving $\left(Q_{o u t}\right)$ during the same time interval $\Delta t$. For the unrestricted sand spit growth case, the sand spit can elongate linearly over the period under consideration, then $Q_{o u t}=0$. The sand conservation equation for the unrestricted spit growth case can be expressed as:

$$
Q_{x}=Q_{i n}=\left(D_{B}+D_{C}\right) \frac{\Delta A}{\Delta t}=\left(D_{B}+D_{C}\right) \frac{B_{s} \Delta_{x}}{\Delta t}
$$

It is noted here that the development area of sand spit $(\Delta A)$ is estimated using the shoreline positions that are detected from the satellite images, and $Q_{x}$ can receive a positive and negative value depending on the defined positive direction of $x$. Hereinafter, the magnitude of LST is defined as $Q=\left|Q_{x}\right|$.

\subsection{Numerical Simulation Method}

The development of the sand spit can be estimated by using the above simple analytical model. However, the sand spit evolution are complex processes in reality, resulting from a combination of the river discharge, tidal discharge, and wave impacts that the analytical model could not take into account. Therefore, the numerical model is more preferable for those cases. This study also attempts to simulate the sand spit development for all tidal inlets using the Delft3D numerical model. The Delft3D model is an open source code and was developed by Delft Hydraulics Research Institute in the Netherlands, and is widely used to simulate hydrodynamics and morphodynamics in inlet areas such as Duong et al. [34,35]. It is integrated from several modules i.e., the wave module (Delft3D-WAVE); the hydrodynamic module (Delft3D-FLOW); and the sediment transport module (Delft3D-SED). The Delft3D-FLOW module solves the depth-averaged or 3D shallow water equations on a rectilinear or curvilinear grid.

Figure 5 shows the Delft3D model grids that were built for the Ly Hoa Inlet and An Du Inlet, respectively. The larger model domain is for the wave transformation simulation model, whereas the small model domain is for the flow and sediment transport simulation models to avoid any wave-shadowing effect at the lateral boundaries.

Table 2 is a summary of the Delft3D model parameters. The time step for the hydrodynamic computation was selected to be equal to $1 \mathrm{~min}$. The horizontal background eddy viscosity and diffusivity were set to be equal to $1 \mathrm{~m}^{2} / \mathrm{s}$. A value of $10^{-6}$ was used for the vertical background viscosity and diffusivity. The wave heights were computed using the roller model [36], including the Delft3D-FLOW module. The flow model is forced mainly tides, river discharges, and waves. The surface wind impacts were excluded due to the small model domain. In addition, the temperature and salinity models were not considered in this study, since the main interests are to investigate the hydrodynamic and morphodynamic regimes. The flow model used 5 days for the ramping period before the actual 
simulation, and the coupling time between the flow and wave models was every $1 \mathrm{~h}$. The sediment transport and morphodynamic computations were carried out by means of the Delft3D-SED module. The updated expression of the TRANSPOR2004 formula $[37,38]$ was used to calculate the bed load and suspended sediment transport. The bed shear stress calculation was based on the van Rijn [37] roughness predictor. The sediment was assumed to be sandy with a measured median grain size according to each region and a sediment density equal to $2.650 \mathrm{~kg} \cdot \mathrm{m}^{-3}$. The dry bed density was set as equal to $1.600 \mathrm{~kg} \cdot \mathrm{m}^{-3}$. The suspended sediment at the beginning of the computation had a representative diameter equal to the $d_{50}$ value. A minimum water depth equal to $0.2 \mathrm{~m}$ was assumed for the sediment transport calculation. All the models were set to allow 12 to $24 \mathrm{~h}$ for hydrodynamic spin up before they executed the bed-level changes. The total simulation duration was set to 1 year for all cases.

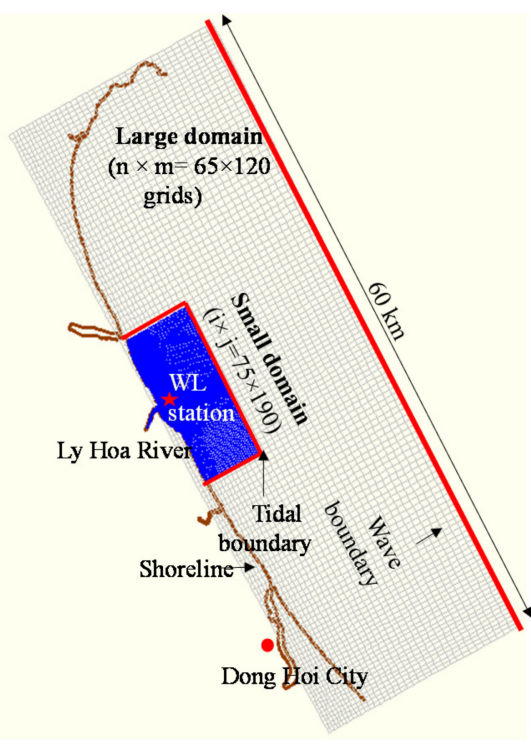

(a) Model grid for the Ly Hoa Inlet

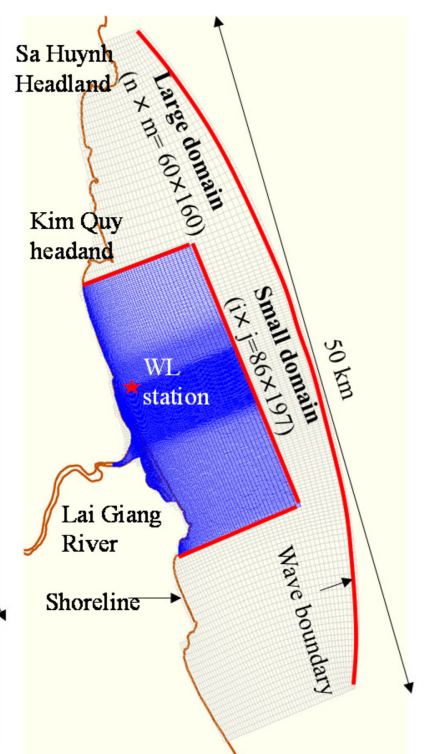

(b) Model grid for the An Du Inlet

Figure 5. Delft3D model grids for (a) the Ly Hoa Inlet (b) the An Du Inlet.

Table 2. Summary of the Delft3D model parameters.

\begin{tabular}{|c|c|c|c|}
\hline Models & Type of Paramaters & Ly Hoa Inlet & An Du Inlet \\
\hline \multirow{3}{*}{ Wave model } & Model domain & $65 \times 120$ nodes & $60 \times 160$ nodes \\
\hline & Model time step & $60 \mathrm{~min}$ & $60 \mathrm{~min}$ \\
\hline & Boundary conditions & $\begin{array}{l}H_{\text {rep }}, T_{\text {rep }}, \theta_{\text {rep }} \text { calculated from } \\
\text { the P1 location (Figure } 5 \text { ) }\end{array}$ & $\begin{array}{l}H_{\text {rep }}, T_{\text {rep }}, \theta_{\text {rep }} \text { calculated from } \\
\text { the P2 location (Figure } 5 \text { ) }\end{array}$ \\
\hline \multirow{6}{*}{ Flow model } & Model domain & $75 \times 90$ nodes & $86 \times 197$ nodes \\
\hline & Total simulation duration & 1 year & 1 year \\
\hline & Model time step & $1 \mathrm{~min}$ & $1 \mathrm{~min}$ \\
\hline & Horizontal eddy viscosity & $1 \mathrm{~m} / \mathrm{s}^{2}$ & $1 \mathrm{~m} / \mathrm{s}^{2}$ \\
\hline & Horizontal eddy diffusivity & $1 \mathrm{~m} / \mathrm{s}^{2}$ & $1 \mathrm{~m} / \mathrm{s}^{2}$ \\
\hline & Chezy bottom friction coefficient & $65 \mathrm{~m}^{1 / 2} \mathrm{~s}$ & $65 \mathrm{~m}^{1 / 2} \mathrm{~s}$ \\
\hline \multirow{7}{*}{$\begin{array}{l}\text { Sediment transport } \\
\text { model }\end{array}$} & Grain size, $d_{50}$ & $0.15 \mathrm{~mm}$ & $0.25 \mathrm{~mm}$ \\
\hline & Dry bed density & $1600 \mathrm{~kg} / \mathrm{m}^{3}$ & $1600 \mathrm{~kg} / \mathrm{m}^{3}$ \\
\hline & Specific density & $2650 \mathrm{~kg} / \mathrm{m}^{3}$ & $2650 \mathrm{~kg} / \mathrm{m}^{3}$ \\
\hline & Thickness of bottom layer & $15 \mathrm{~m}$ & $15 \mathrm{~m}$ \\
\hline & Settling velocity & $0.25 \mathrm{~mm} / \mathrm{s}$ & $0.25 \mathrm{~mm} / \mathrm{s}$ \\
\hline & Acreation morphological factor & 1 & 1 \\
\hline & Calculation formula & Van Rijn's Formula & Van Rijn's Formula \\
\hline
\end{tabular}




\section{Sand Spit Evolution at Ly Hoa Inlet and An Du Inlet}

\subsection{Long-Term Morphological Changes in the Ly Hoa Inlet and An Du Inlet by Satellite Image Analysis}

Figures 6 and 7 present some typical morphological changes in the Ly Hoa Inlet and An Du Inlet that were obtained from the analysis of Landsat images and Google Earth images from 1988 to 2019. In these figure, the extracted shoreline positions were indicated by the solid lines, while the position of the estuary was indicated by a white arrow, and a vertical dashed line indicates the initial river mouth location in 1988. In addition, Figures $6 \mathrm{e}$ and $7 \mathrm{e}$ show that a coordinate system $(x, y)$ was set up to quantify the morphological characteristic parameters of the sand spit. The long-term evolution of the Ly Hoa inlet and An Du inlet can be briefly described as follows:
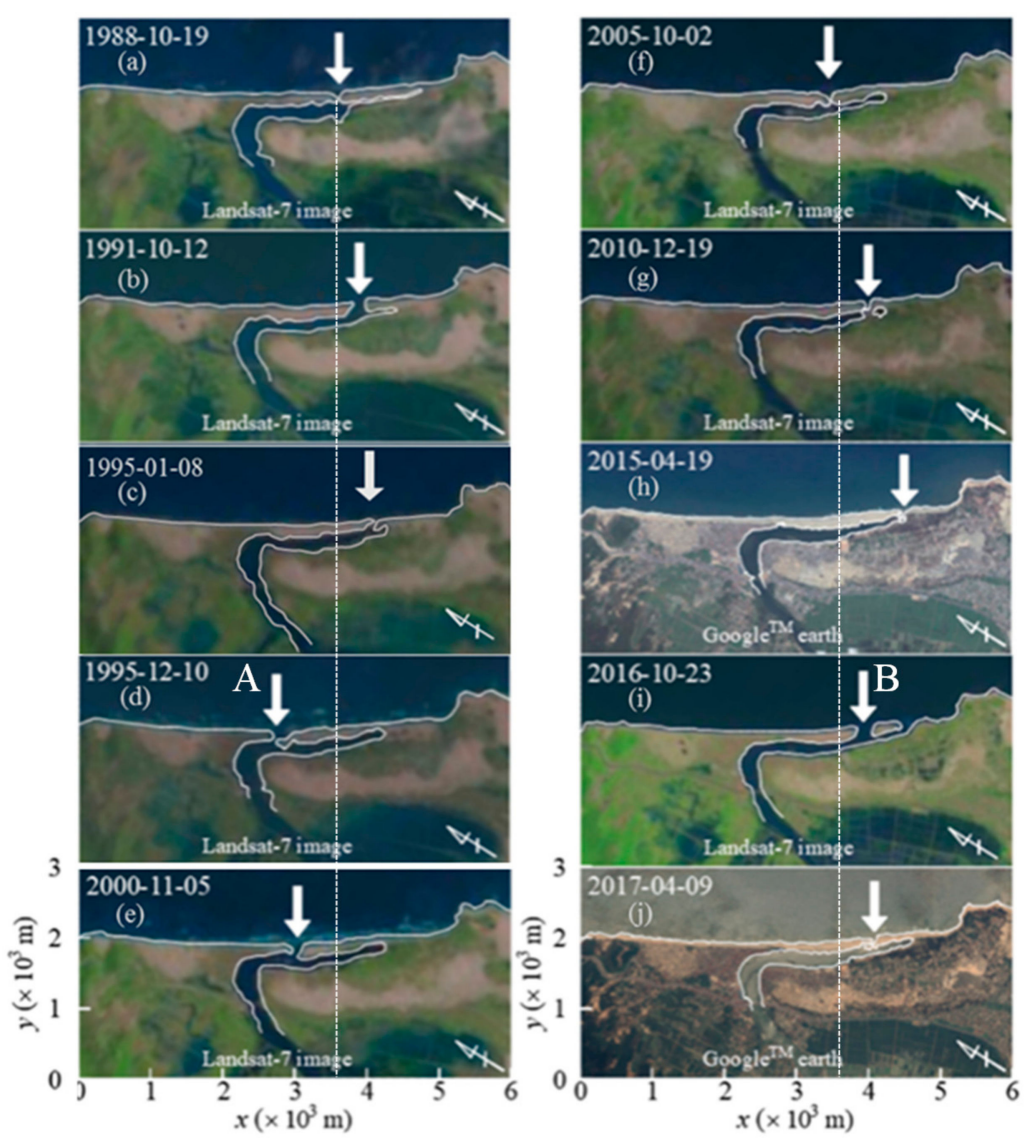

Figure 6. The selected satellite images of the long-term morphological changes at the Ly Hoa Inlet, Quang Binh province from (a-j) 19 October 1988 to 9 April 2017.

For the Ly Hoa Inlet, there was initially a long sand spit on the left side of the river mouth, and the inlet entrance was located at about $x=3500 \mathrm{~m}$. Within 7 years, the inlet was gradually moved to the right side until January 1995 (Figure 6c). Subsequently, the sand spit was breached in December 1995. The mechanism of this breaching event highly corresponded to the extreme river flood event, as denoted as character $\mathrm{A}$ in Figure 2(a1). At that time, the river discharge reached the highest value in Ly Hoa river at $700 \mathrm{~m}^{3} / \mathrm{s}$. After that, the inlet location tended to migrate to the right side again until April 2015 (Figure 6h). It is noted that the inlet mouth width was remarkably narrowed in 2015. Two breaching places were observed on the image in October 2016, as seen in Figure 6i. The second breaching of the Ly Hoa sand spit was believed to be caused by the increase in the river water level during the severe flood event at the end of 2015 in this area, as denoted by character B in Figure 2(a1). Finally, after about one year, the former inlet mouth was completely closed and the new breached place was maintained as a new inlet mouth (Figure 6j). The morphodynamic changes in the Ly Hoa sand spit 
were a really dynamic process. The maximum of inlet migration length was about $2 \mathrm{~km}$. The dominant direction of the sand spit development was from left to right (or to the southward direction) in the Ly Hoa case.
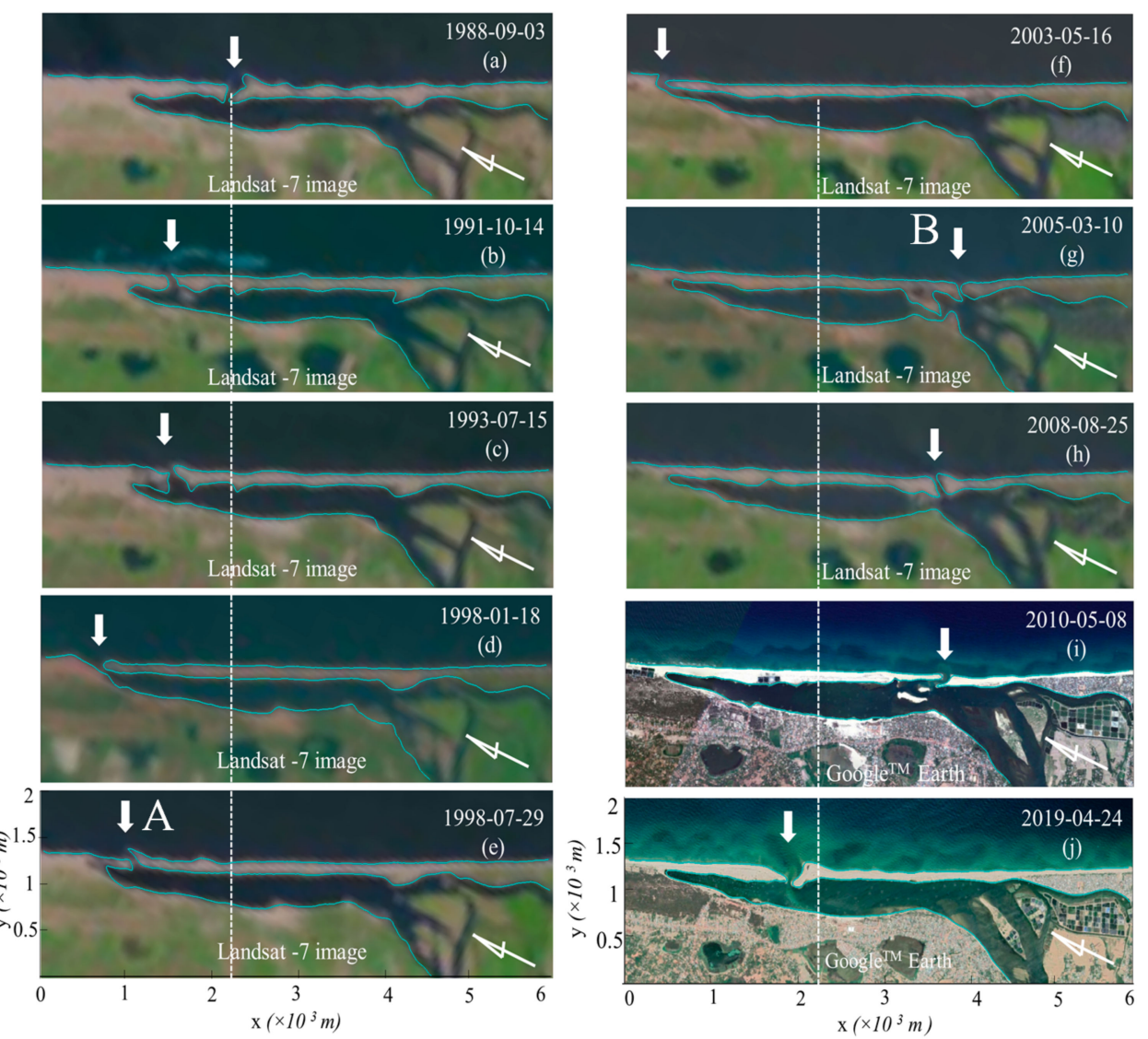

Figure 7. The selected satellite images of the long-term morphological changes at the An Du Inlet, Binh Dinh province from (a-j) 3 September 1988 to 24 April 2019.

For the An Du Inlet, the inlet entrance was located at about $x=2000 \mathrm{~m}$ in September 1988 (Figure 7a). Hence, over 10 years, the An Du Inlet continuously migrated to the left (or to the north direction) by a distance of about $1600 \mathrm{~m}$, as shown from Figure $7 \mathrm{~b}-\mathrm{f}$. This suggests a dominant LST from the right. A first breach of the sand spit happened in July 1998 at around $x=1000 \mathrm{~m}$ (Figure 7e). After that, the inlet again moved to the left and reached the most left end in May 2003 (see Figure 7f). A left sand spit retreated in response to the extension of the right sand spit. In addition, a second breach of the An Du sand spit was observed in March 2005 at the location of $x=3500 \mathrm{~m}$ (Figure 7g). Figure $7 \mathrm{~h}-\mathrm{j}$ indicate that the inlet continued to migrate northward again. Interestingly, in Figure 7i,j the morphological analysis was conducted using Google Earth images, with a higher resolution than that of Landsat images. From these images, there was obviously no vegetation covering the spit surface. This might due to a frequent wave overtopping on the $\mathrm{An} \mathrm{Du}$ sand spit area. It is noted that the first and second breaching of the An Du sand spit are denoted by the characters A and B in Figure 2(b1) and Figure 7. According to Figure 2(b1), the second breaching B strongly corresponded to the severe river flooding event with the maximum river discharge of $2500 \mathrm{~m}^{3} / \mathrm{s}$, whereas the first breaching A happened at a very low river discharge. According to the interviews with the local government by the authors, the cause of breach A was the implementation of an artificial beach cut on the sand spit before the rainy season to avoid the flood inundation to surrounding estuary areas. This was carried out by the local government because this area frequently experienced coastal inundation problems.

Similar sand spit development and breaching phenomena were also observed in the river mouths in the Fukushima Prefecture [39] and Miyagi Prefecture in Japan [40]. However, the closing phenomenon 
of the river mouth was controlled by jetty constructions at the river mouth, and then the development of the sand spit was no longer observed. Meanwhile, many river mouths in Vietnam still remain their natural states without being regulated by human activities. According to the study by Duy et al. [20], at Cua Lo river mouth along the central coast of Vietnam, the elongation together with the migration of the sand spit could also cause the erosion of the opposite shoreline at the downdrift side. Therefore, the study of various characteristic changes in the sand spit at the river mouth plays an important role in the management of the river mouth.

\subsection{Evaluation of the Longshore Sediment Transport Rate at the Ly Hoa Inlet and An Du Inlet by Satellite Images}

In order to gain better understanding of this complex coastal system evolution, the sand spit elongation rate and area change will be quantitatively investigated. Figures 8a and 9a show the definition sketch of the left sand spit of Ly Hoa Inlet and the right sand spit of An Du Inlet, in which $x_{L}$ and $x_{R}$ are the tip coordinates and $A_{L}$ and $A_{R}$ are the areas of the sand spits, where the subscripts $L$ and $R$ denote left and right. The reference coordinates for the Ly Hoa sand spit and An Du sand spit were defined at $x=2500 \mathrm{~m}$ and $x=5000 \mathrm{~m}$, respectively.
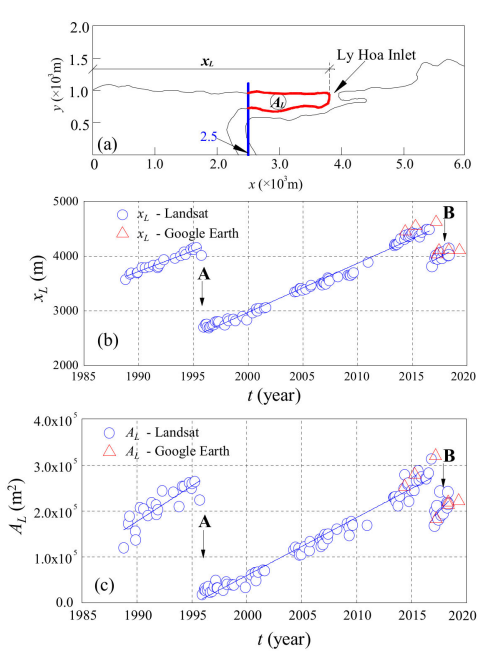

Figure 8. (a) Definition sketch of the left sand spit of Ly Hoa Inlet, (b) Time variations of the tip coordinate $\left(x_{L}\right),(\mathbf{c})$ Time variations of the sand spit area $\left(A_{L}\right)$.
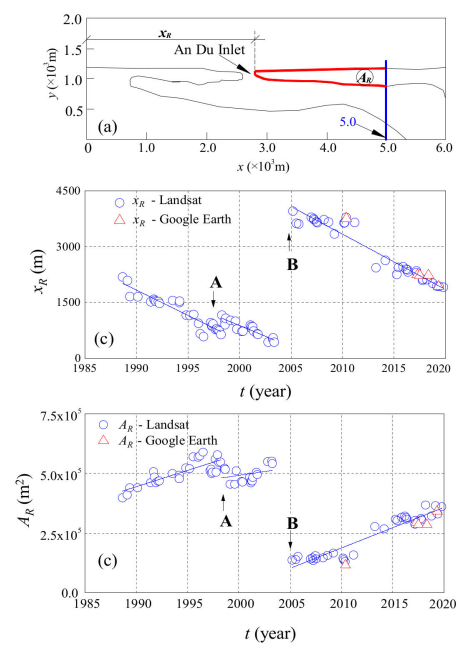

Figure 9. (a) Definition sketch of the right sand spit of An Du Inlet, (b) Time variations of the tip coordinate $\left(x_{R}\right),(\mathbf{c})$ Time variations of the sand spit area $\left(A_{R}\right)$. 
The time variations of the tip coordinates and sand spit areas for the Ly Hoa sand spit and An Du sand spit are illustrated in Figures 8 and 9, respectively. In these figures, the breaching events A and $\mathrm{B}$ and the analysis results from the Landsat (blue circle) as well as the Google Earth (red triangular) images are shown. Both results show a relatively similar variation, despite a significant difference in the image resolution. This indicates that the analyzed results from the Landsat images also gave high-accuracy results. Applying the linear regression method for these three different sand spit development periods, the sand spit elongation rates can be obtained for each tidal inlet, as shown from Equation (2) to Equation (7) as follows.

For the Ly Hoa Inlet:

October 1988-September 1995:

$$
x_{L}=76.0 \times(t-1988)+3.338 \times 10^{3} \quad(m)
$$

December 1995-April 2015:

$$
x_{L}=89.7 \times(t-1995)+2.521 \times 10^{3} \quad(m)
$$

August 2015-May 2018:

$$
x_{L}=109 \times(t-2016)+3.817 \times 10^{3} \quad(m)
$$

$t$ is the time (year).

For the An Du Inlet:

September 1988-March 1998:

$$
x_{R}=-136 \times(t-1985)+2.516 \times 10^{3} \quad(m)
$$

April 1998-May 2003:

$$
x_{R}=-118 \times(t-1988)+1.104 \times 10^{3} \quad(m)
$$

March 2005-October 2019:

$$
x_{R}=-146 \times(t-2005)+4.069 \times 10^{3} \quad(m)
$$

$t$ is the time (year).

It is interesting to note that although several breachings of the sand spit happened over 30 years, the sand spit elongation rates at the Ly Hoa Inlet and An Du Inlet were more or less constant, at a rate of $91 \mathrm{~m} / \mathrm{y}$ to the south and $140 \mathrm{~m} / \mathrm{y}$ to the north, respectively. The mechanisms for a constant elongation rate are due to the seasonal monsoon wave regime and the oblique wave incident to the shore-normal direction. The seasonal wave actions are the dominant driving forces in the morphological development of inlets along the central coast of Vietnam. Because the monsoon wave regime did not change over long period of time, the rate of spit movement was expected to be almost constant.

Using the same linear regression method for the data in Figures $8 \mathrm{c}$ and $9 \mathrm{c}$, the growth rates of the sand spit area for both inlets are shown from Equation (8) to Equation (13) as follows:

For the Ly Hoa Inlet:

October 1988-September 1995:

$$
\frac{d A_{L}}{d t}=1.55 \times 10^{4} \quad\left(\mathrm{~m}^{2} / \mathrm{y}\right)
$$


December 1995-April 2015:

$$
\frac{d A_{L}}{d t}=1.27 \times 10^{4} \quad\left(m^{2} / y\right)
$$

August 2015-May 2018:

$$
\frac{d A_{L}}{d t}=2.48 \times 10^{4} \quad\left(m^{2} / y\right)
$$

For the An Du Inlet:

September 1988-March 1998:

$$
\frac{d A_{R}}{d t}=1.37 \times 10^{4} \quad\left(m^{2} / y\right)
$$

April 1998-May 2003:

$$
\frac{d A_{R}}{d t}=0.82 \times 10^{4} \quad\left(m^{2} / y\right)
$$

March 2005-October 2019:

$$
\frac{d A_{R}}{d t}=1.75 \times 10^{4} \quad\left(m^{2} / y\right)
$$

Substituting separately Equations (8)-(13) into Equation (1) with the values of berm height $D_{B}=3 \mathrm{~m}$, and the depth of closure $D_{C}=10 \mathrm{~m}$ for both the Ly Hoa and An Du coastal areas according to Hung [41], the LST rates for each period are expressed from Equation (14) to Equation (19) as follows. For the Ly Hoa Inlet:

October 1988-September 1995

$$
Q_{x}=2.02 \times 10^{5} \quad\left(m^{3} / y\right)
$$

December 1995-April 2015:

$$
Q_{x}=1.65 \times 10^{5} \quad\left(m^{3} / y\right)
$$

August 2015-May 2018:

$$
Q_{x}=3.23 \times 10^{5} \quad\left(m^{3} / y\right)
$$

For the An Du Inlet:

September 1988-March 1998:

$$
Q_{x}=-1.78 \times 10^{5} \quad\left(m^{3} / y\right)
$$

April 1998-May 2003:

$$
Q_{x}=-1.07 \times 10^{5} \quad\left(m^{3} / y\right)
$$

March 2005-October 2019:

$$
Q_{x}=-2.27 \times 10^{5} \quad\left(m^{3} / y\right)
$$

In conclusion, the averaged LST rates at the Ly Hoa Inlet and An Du Inlet by long-term satellite image analysis are estimated to be equal to $2.30 \times 10^{5} \mathrm{~m}^{3} / \mathrm{y}$ to the south and $-1.71 \times 10^{5} \mathrm{~m}^{3} / \mathrm{y}$ to the north, respectively. 
3.3. Evaluation of the Longshore Sediment Transport Rate at the Ly Hoa Inlet and An Du Inlet by the Delft3D Numerical Model

(a) Model calibration

The measured water surface elevations from two stations as shown in Figure 5 were used for the model calibration process. The root-mean-square error (RMSE) was used to assess the accuracy of the model. These criteria are defined in Equation (20) as follows:

$$
\text { RMSE }=\sqrt{\frac{\sum(M-D)^{2}}{n}}
$$

where $D$ is the observational data, $M$ is the corresponding modeled data, $n$ is total number of pairs.

As a calibrated result, the obtained RMSE values for the Ly Hoa and An Du water level data are $0.081 \mathrm{~m}$ and $0.036 \mathrm{~m}$, respectively. These small differences indicate that the hydraulic model obtained a high accuracy. Hence, the model is ready for the long-term simulation of sand spit development in both inlet areas.

(b) Modeled longshore sediment transport rate

As discussed above, the Vietnam coastal area is highly influenced by the seasonal monsoon regime, which is characterized by large northeast (NE) waves from October to March and calm southeast (SE) waves from April to September every year. Consequently, the tidal inlet entrance morphologies often suffer from a dynamic seasonal evolution due to a distinct difference in the direction of wave-induced longshore sediment transport (LST) between the two monsoon seasons. The NE waves during the winter generate a southward littoral drift along the central coast, whereas a northward littoral drift is caused by the SE waves during the summer. Figures $10 \mathrm{~b}$ and $11 \mathrm{~b}$ show an example of the Delft3D numerical simulation results for the instantaneous and accumulated sediment transport through the T1 profile over one year. It is clear seen that the instantaneous sediment transport fluctuations correspond to the seasonal wave regime, which fluctuated strongly during the wintertime and weakly during the summertime.

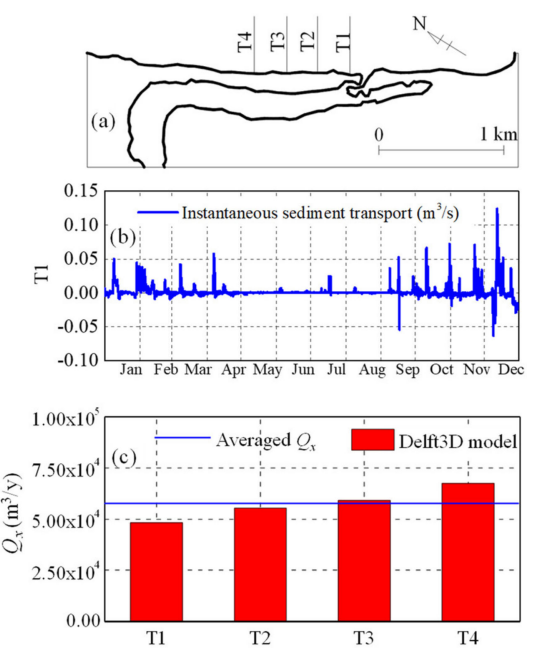

Figure 10. (a) Location of profiles. (b) Instantaneous sediment transport rate through the T1-profile.

(c) Total cumulative sediment transport through 4 profiles at the Ly Hoa sand spit.

Figure 10c shows the annual total cumulative LST rate estimated by the Delft3D numerical model through four profiles along the Ly Hoa sand spit. The reduced trend of total cumulative sediment transport from T1 to T4 means that the left sand spit at the Ly Hoa River Mouth is accreting to the right (i.e., to the south), which is in good agreement well with the analyzed results from the satellite image. Hence, the average LST rate along the coast of the Ly Hoa River mouth, which was determined by 
taking an average value of the total accumulated sediment transport through four profiles from $\mathrm{T} 1$ to $\mathrm{T} 4$, was estimated at a rate of $Q=0.68 \times 10^{5}\left(\mathrm{~m}^{3} / \mathrm{y}\right)$.

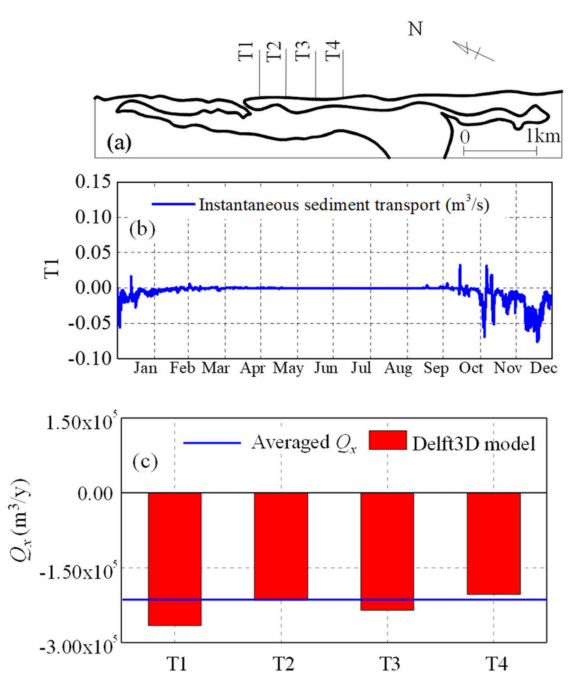

Figure 11. (a) Location of profiles. (b) Instantaneous sediment transport rate through the T1-profile.

(c) Total cumulative sediment transport through 4 profiles at the An Du sand spit.

Similarly, Figure 11c shows the annual total cumulative LST rate at four profiles along the right sand spit in the An Du River Mouth. The increasing trend of total cumulative sediment transport from T1 to T4 suggests that the sand spit on the right of An Du Inlet is dominantly developed to the north. The averaged LST rate at the An Du coast is estimated at about $Q=-1.95 \times 10^{5} \mathrm{~m}^{3} / \mathrm{y}$.

Figure 12 plots the wave rose results of the Delft3D-Wave model in the wave nearshore zone area along the coast of Ly Hoa and An Du. Based on these results, it is clearly seen that when the wave approaches the nearshore area of the Ly Hoa coast, the dominant incident wave direction in both winter and summer tends to deviate from the shore-normal direction towards the north (Figure 12a), causing the dominant LST to go to the south direction. Meanwhile, the angle between the incident wave direction and the shore-normal direction in the An Du coast deviates to the south during both winter and summer, as seen in Figure 12b, causing the wave-induced LST direction to tend to the north. These seasonal wave transformations in the nearshore regions are the mechanisms that explain why the sand spit at Ly Hoa Inlet grows in a southward direction, whereas the sand spit of An Du elongates in a northward direction.
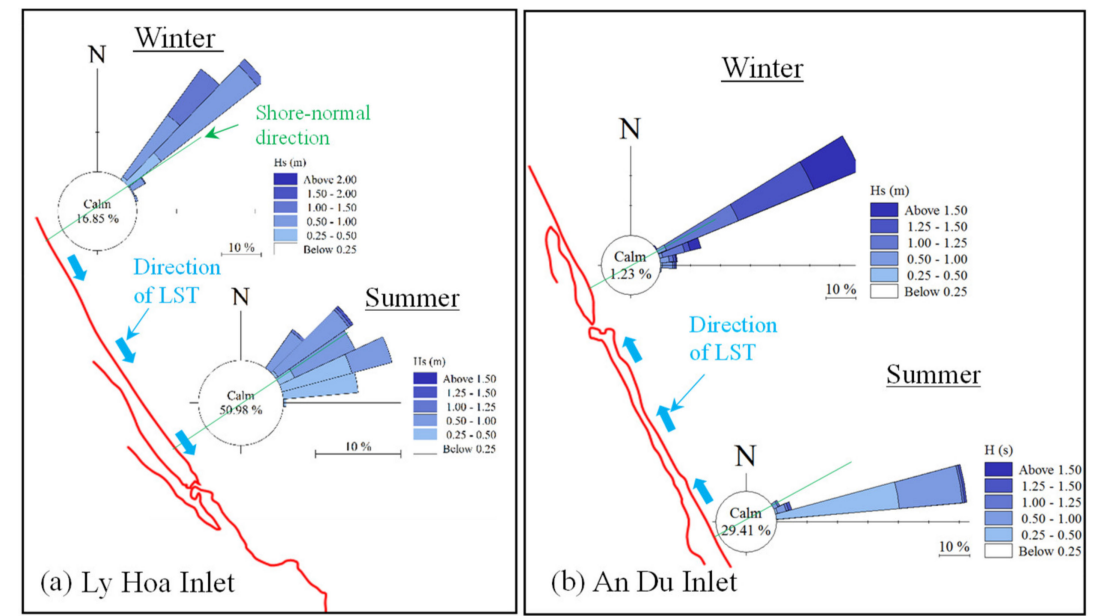

Figure 12. Wave roses at the nearshore area from Delft3D model results at (a) the Ly Hoa Inlet, (b) the An Du Inlet. 


\section{Comprehensive Study on the Sand Spit Evolution at Tidal Inlets in the Central Coast of Vietnam}

\subsection{Summary of Study Sites}

Tidal inlets along the central coast of Vietnam are characterized by seasonal variations due to the impacts of the monsoon wave regimes and rainy/dry seasons. Natural long sand spits often exist at the entrances of inlets. The sand spit evolution is dependent on a combination of impacts from wave- and tidal-induced currents, as well as river flood discharge. The inlet entrance may close during the dry season, when a strong littoral drift transports a large amount of sediment into the entrance. Whereas, the tidal inlet's mouth may expand at the existing entrance location or breache at a new location on the sand spit during a severe flood event in the rainy season.

In this section, a comprehensive study will be performed by combining the current study results with the results from our group's studies at some other tidal inlets along the central coast of Vietnam, such as the Ken and Phan Inlets by Duc Anh [16], the Cua Lo Inlet by Duy et al. [20], and the Loc An Inlet by Duc Anh [17]. It is noted that the exact same methodology was utilized among these studies in order to enable a consistent comparison. Figure 13 illustrates the location of six tidal inlets and their entrance morphologies. Table 3 is a summary of the morphodynamic characteristics of six tidal inlets along the central coast of Vietnam. It is clearly seen that each tidal inlet has a distinct difference in its morphodynamic characteristics for instance, the river length, river catchment area, and sand spit width $\left(B_{S}\right)$, as well as the sand spit growth rate $\left(R_{s}\right)$.

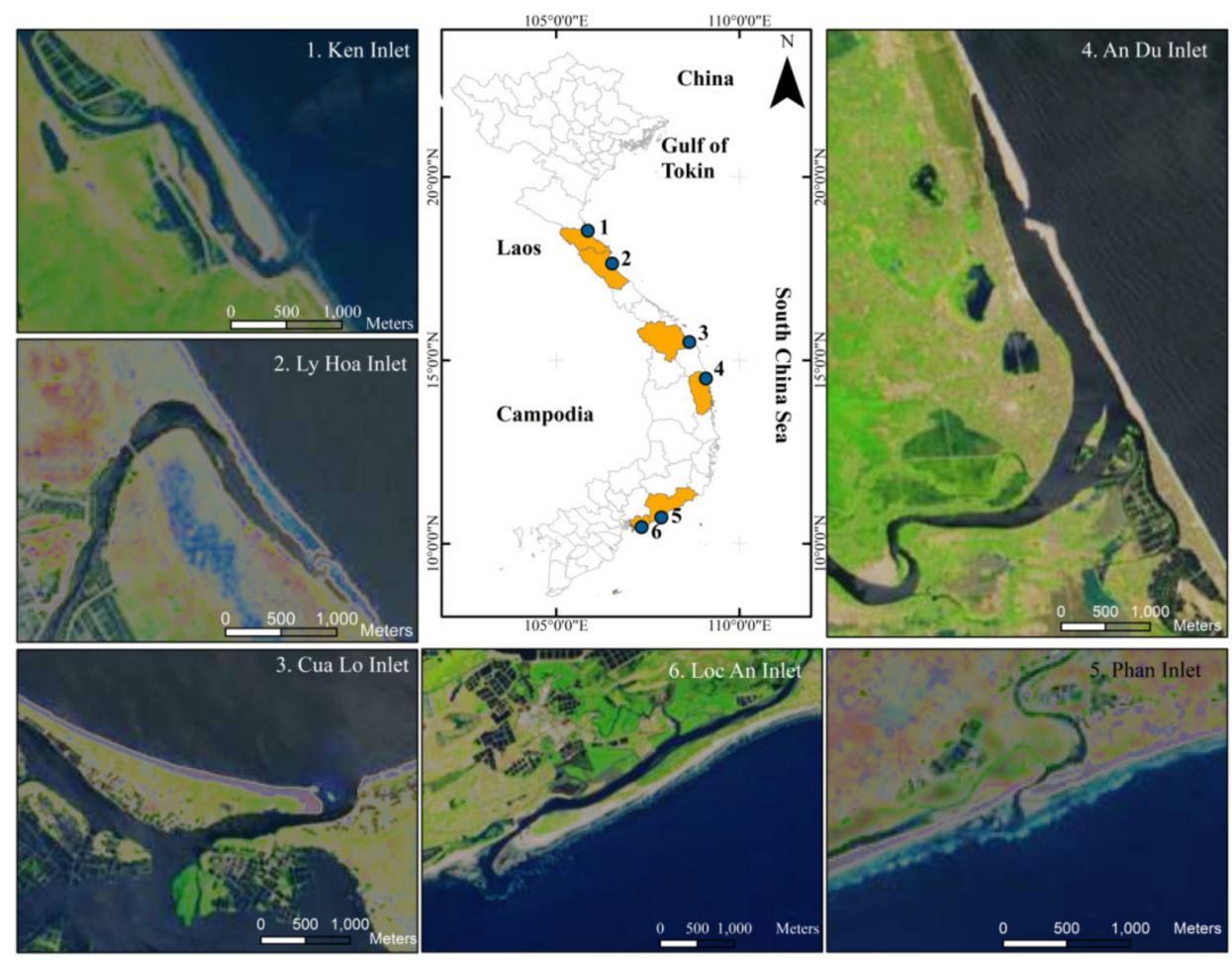

Figure 13. Location and morphology of six tidal inlets along the center coast of Vietnam. 
Table 3. Summary of major morphodynamic characteristics of six tidal inlets in the central coast of Vietnam.

\begin{tabular}{|c|c|c|c|c|c|c|c|c|c|c|}
\hline \multirow[t]{2}{*}{ No. } & \multirow[t]{2}{*}{ Inlet } & River Length & Basin Area & $\begin{array}{c}\text { Mean Spring } \\
\text { Tide }\left(h_{\text {tide }}\right)\end{array}$ & $\begin{array}{c}\text { Mean Inlet } \\
\text { Depth }(d)\end{array}$ & $D_{C}+D_{B}$ & $\begin{array}{c}\text { Spit Width } \\
\left(B_{s}\right)\end{array}$ & $\begin{array}{l}\text { Spit Growth rate } \\
\left(R_{s}\right)\end{array}$ & $\begin{array}{l}\text { LST by Satellite } \\
\text { Image }\left(Q_{\text {Sat. }}\right)^{*}\end{array}$ & $\begin{array}{c}\text { LST by Delft3D } \\
\left(Q_{\text {Delft }}\right)^{*}\end{array}$ \\
\hline & & $(\mathrm{km})$ & $\left(\mathrm{km}^{2}\right)$ & (m) & (m) & (m) & (m) & $(\mathrm{m} / \mathrm{y})$ & $\left(\mathrm{m}^{3} / \mathrm{y}\right)$ & $\left(\mathrm{m}^{3} / \mathrm{y}\right)$ \\
\hline 1 & Ken Inlet [16] & 15 & 120 & 1.0 & 1.63 & $8+2$ & 180 & 55 & $1.33 \times 10^{5}$ & $0.58 \times 10^{5}$ \\
\hline 2 & $\begin{array}{l}\text { Ly Hoa Inlet } \\
\text { (Present study) }\end{array}$ & 25 & 177 & 0.6 & 0.88 & $10+3$ & 130 & 90 & $1.65 \sim 3.23 \times 10^{5}$ & $0.68 \times 10^{5}$ \\
\hline 3 & Cua Lo Inlet [20] & 70 & 436 & 0.75 & 2.53 & $6+2$ & 280 & 50 & $1.6 \times 10^{5}$ & $0.84 \times 10^{5}$ \\
\hline 4 & $\begin{array}{c}\text { An Du Inlet } \\
\text { (Present study) }\end{array}$ & 85 & 1466 & 0.47 & 1.78 & $10+3$ & 70 & 140 & $1.07 \sim 2.27 \times 10^{5}$ & $1.95 \times 10^{5}$ \\
\hline 5 & Phan Inlet [16] & 40 & 218 & 0.75 & 1.37 & $6+2$ & 60 & 183 & $1.18 \sim 1.7 \times 10^{5}$ & $1.62 \times 10^{5}$ \\
\hline 6 & Loc An Inlet [17] & 90 & 1200 & 1.2 & 1.31 & $6+2$ & 150 & 85 & $2.0 \times 10^{5}$ & $1.42 \times 10^{5}$ \\
\hline
\end{tabular}


Figure 14 shows the LST results using the satellite images $\left(Q_{\text {sat }}\right)$ versus the Delft3D numerical model $\left(Q_{\text {Delft }}\right)$. It is interesting to note that although the $Q_{\text {sat. }}$. was estimated using a rather simple method by Kraus [32], it was in the same order of magnitude compared to the numerical result obtained from the sophisticated Delft3D model. In addition, the LST rate in the vicinity of the tidal inlets along the central coast of Vietnam varies in a highly limited range from $0.6 \times 10^{5}$ to $2.0 \times 10^{5} \mathrm{~m}^{3} / \mathrm{y}$.

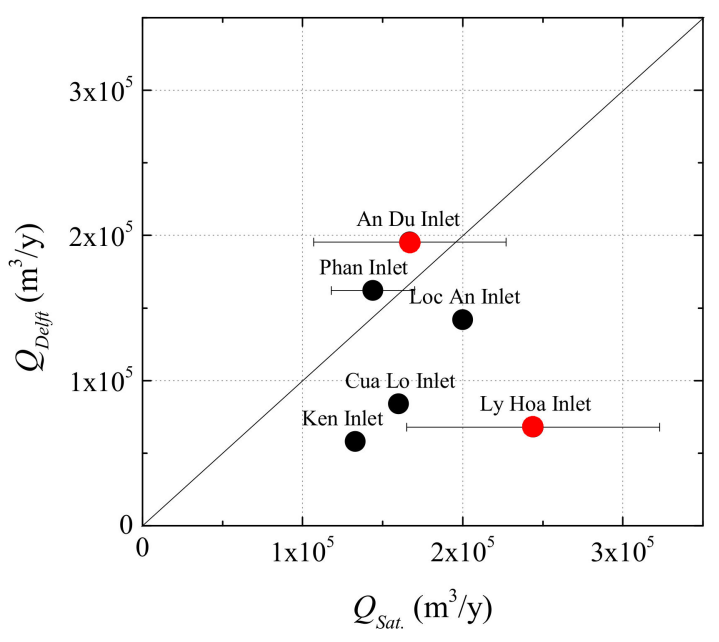

Figure 14. LST rate by the satellite image analysis results versus the Delft3D numerical model results.

\subsection{Estimation of the Sand Spit Growth Rate}

The quantitative relationship between $R_{S}$ and $B_{S}$ based on the satellite image analysis results from six tidal inlets along the central coast of Vietnam, as shown in Table 3, is plotted and denoted as black-filled circles in Figure 15, in which the red circle indicates the tidal inlets with breaching occurrence. It is interesting to note that the breaching happened along a relatively small width of the sand spit. In addition, Figure 15 clearly shows that the sand spit growth rate $\left(R_{S}\right)$ is inversely proportional to the sand spit width $\left(B_{S}\right)$. If the spit width is smaller, there will be a more rapid development of the sand spit.

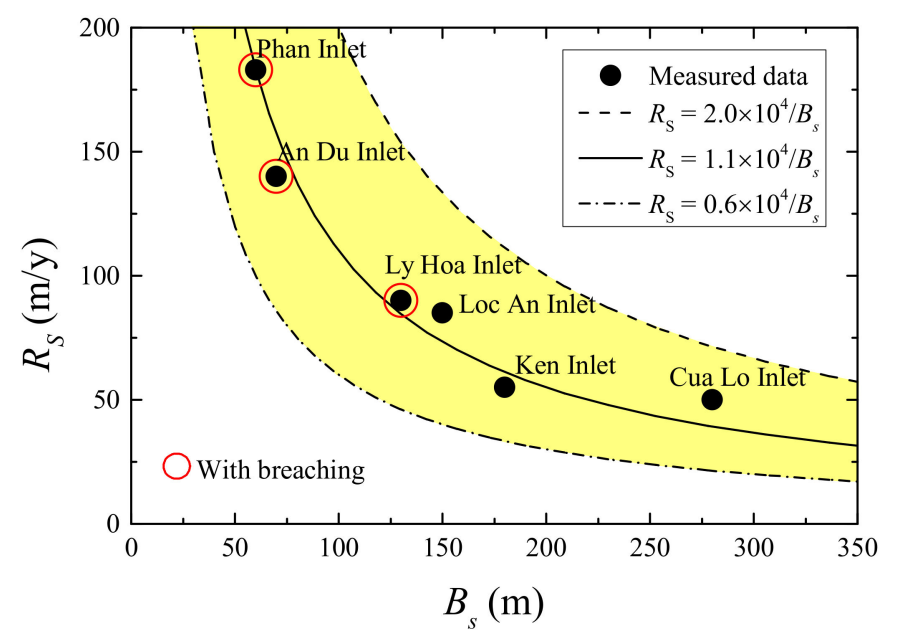

Figure 15. Relationship between the sand spit growth rate and sand spit width.

Tung [25] has developed a conceptual model to explain the evolution of a tidal inlet. In his conceptual model, the inlet entrance is forced both by the wave-induced LST (spit elongation in the downdrift direction) and the river-generated currents, which flush sediment out of the inlet channel (breaching or widening of the inlet entrance). Moreover, all the mathematical models for a spit growth, which were developed by Tanaka et al. [31], Kraus [32] and Larson et al. [33], were also 
based the assumption that the entire LST from the updrift side corresponds to an increase in the spit length together with a constant and given spit width $\left(B_{s}\right)$ during the spit growth process. Based on the conservation equation for sand of an unrestricted spit growth, the following Equation (21) can be applied.

$$
Q=R_{s} B_{S}\left(D_{B}+D_{C}\right)
$$

or

$$
R_{S}=\frac{Q}{\left(D_{B}+D_{C}\right)} \frac{1}{B_{S}}=\alpha \frac{1}{B_{S}}
$$

where $\alpha$ can be defined as the changing rate coefficient $\left(\mathrm{m}^{2} / \mathrm{y}\right)$. The inverse relationship between $R_{S}$ and $B_{S}$ as suggested by the measured data in Figure 15 is also confirmed by Equation (22).

Since the $B_{S}$ value was assumed to be constant during the elongation process, the $R_{S}$ value varies mainly due to the changes in LST, $Q$. Hence, Figure 16 shows the contour map of Equation (22) in a log-plot diagram, corresponding to a wide range of the $\alpha$ value from $10^{3}$ to $10^{5}\left(\mathrm{~m}^{2} / \mathrm{y}\right)$. If assuming that the magnitude of LST $Q$ along the central coastal of Vietnam receives a value in the above limited range and the sum of $\left(D_{B}+D_{C}\right)$ equal $10 \mathrm{~m}$, hence, the relationship between $R_{S}$ and $B_{S}$ can be plotted. The results are denoted as a yellow area in Figures 15 and 16. In particular, the best fit-line for the measured data was obtained as $Q=1.1 \times 10^{5} \mathrm{~m}^{3} / \mathrm{y}$. Therefore, Equation (22) becomes as follows

$$
R_{S}=\frac{1.1 \times 10^{4}}{B_{S}} \quad(m / y)
$$

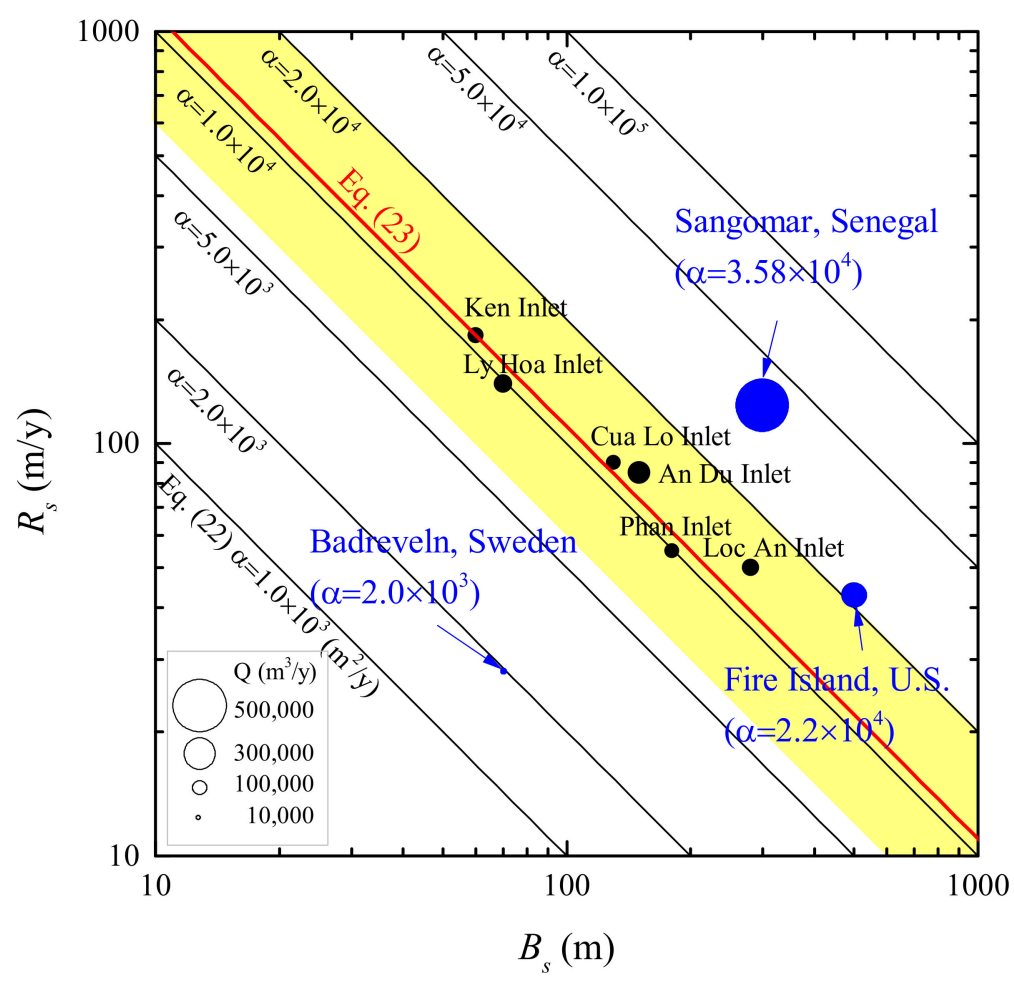

Figure 16. Relationship between sand spit growth rate and sand spit width.

Equation (23) can be used to predict the sand spit growth rate using a single unknown parameter $B_{s}$ for the inlets in the center of Vietnam. Moreover, the yellow area that corresponds to the lower limit of $Q=0.6 \times 10^{5} \mathrm{~m}^{3} / \mathrm{y}$ and upper limit of $Q=2.0 \times 10^{5} \mathrm{~m}^{3} / \mathrm{y}$ can be considered as the lower and upper errors when applying Equation (23).

Three measured data points of the unrestricted sand spit growth rates at the Sangomar spit in Senegal, the Badreveln spit in Sweden, and Fire Island Inlet in the U.S., as reported in studies by Palalane et al. [42] and Hoan et al. [43], are summarized in Table 4 and illustrated as blue-filled circles in 
Figure 15. According to the study by [42], the averaged LST along the $20 \mathrm{~km}$-long Sangomar spit from 1927 to 1987 was estimated to be around 465,000 m³/y. Meanwhile, the average LST at the Fire Island spit from 1933 to 2010 and the $3 \mathrm{~km}$-long Badreveln spit from 1916 to1994 were, respectively, estimated to be about $220,000 \mathrm{~m}^{3} / \mathrm{y}$ and $10,000 \mathrm{~m}^{3} / \mathrm{y}$ [43]. As can be seen from this figure, these measured data points are comparable with the corresponding contour line that derived in the current study.

Table 4. Summary of the morphodynamic characteristics of the spit at Sangomar, Badreveln and Fire Island inlets.

\begin{tabular}{ccccccc}
\hline \multirow{2}{*}{ No. } & \multirow{2}{*}{ Inlet } & $\boldsymbol{D}_{\boldsymbol{C}}+\boldsymbol{D}_{\boldsymbol{B}}$ & Spit Width $\left(\boldsymbol{B}_{\boldsymbol{s}}\right)$ & Spit Growth Rate $\left(\boldsymbol{R}_{\boldsymbol{s}}\right)$ & $\mathbf{L S T}(\mathbf{Q})$ & $\alpha$ \\
\cline { 3 - 7 } & $\mathbf{( m )}$ & $\mathbf{( m )}$ & $\mathbf{( m / y )}$ & $\left(\mathbf{m}^{\mathbf{3}} / \mathbf{y}\right)$ & $\left(\mathbf{m}^{\mathbf{2}} / \mathbf{y}\right)$ \\
\hline 1 & Sangomar spit [42] & $11^{*}+2$ & 300 & 124 & $4.65 \times 10^{5}$ & $3.58 \times 10^{4}$ \\
2 & Badreveln spit [43] & $4+1$ & 70 & 28 & $1.0 \times 10^{4}$ & $2.0 \times 10^{3}$ \\
3 & Fire Island spit [43] & $8+2$ & 500 & 43 & $2.20 \times 10^{5}$ & $2.2 \times 10^{4}$ \\
\hline \multicolumn{5}{c}{ * according to Dennis et al. [44]. }
\end{tabular}

\subsection{Relationship of the Sand Spit Width and Inlet Water Depth}

To explain why the values of $B_{S}$ are different among the six tidal inlets, the relationship between the inlet water depth $(h)$ and sand spit width $\left(B_{s}\right)$ is plotted in Figure 17 using the data in Table 3. Here, the inlet water depth $(h)$ is defined as a sum of the mean inlet water depth $(d)$ and the mean spring tide level $\left(h_{\text {Tide }}\right)$. The results indicate that if the inlet water depth is large, the sand spit width is also large and vice versa. This mechanism can be explained by the impacts of wave energy dissipation. In a shallow water inlet, waves tend to break in the offshore area so most of the wave energy is dissipated before approaching the inlet entrance area. However, at a deeper inlet, waves can propagate further into the river mouth, and the sediment transport rate will be stronger in this case. Therefore, sand can move into the river upstream, leading to a larger sand spit width. On the contrary, this process slows down the elongation speed of the sand spit, as discussed above.

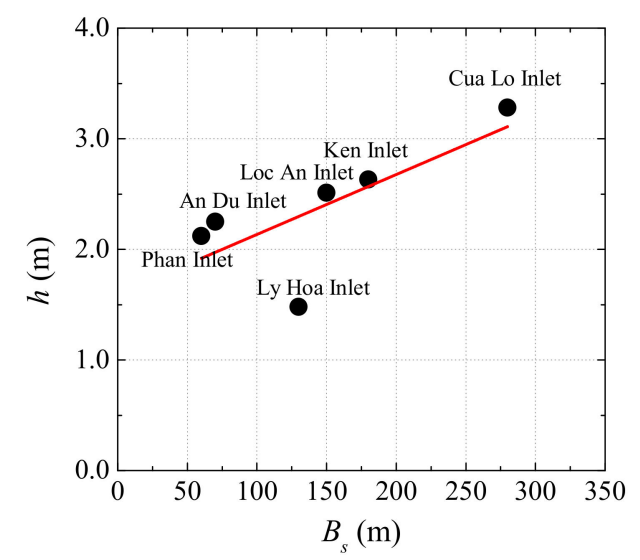

Figure 17. Relationship between the sand spit width and tidal inlet depth.

\section{Conclusions}

In this research, a comprehensive study of the natural behavior and sand spit evolution at tidal inlets along the central coast of Vietnam is conducted. Various morphodynamic characteristic changes in the sand spits are analyzed and discussed based on both the satellite images collected over about 40 years and the numerical Delft3D model. The net LST rates estimated both by the analytical method and the numerical method are in a similar order of magnitude.

The longshore sediment transport rates, which were caused by the action of seasonal waves and currents are the main mechanisms for sand spit evolutions and inlet migrations in the central coast region of Vietnam. River water level rise during severe floods can cause the breaching at portion of low elevation on the spits due to overflow from the river side. This phenomenon occurs frequently in 
small and narrow tidal inlets, such as the Phan Inlet, An Du Inlet, and Ly Hoa Inlet. It is especially interesting that the sand spit growth rate was almost unchanged before and after each breaching.

A remarkable finding based on the current study is that the sand spit growth rate is inversely proportional to the sand spit width. Based on the conservation equation for sand, a simple formula for predicting the unrestricted sand spit growth rate as a function of the LST and the sand spit width was developed. Equation (23) was calibrated using the comprehensive data for the central coast of Vietnam. However, when we apply this relationship to other places, it is necessary to estimate the LST rate and sand spit width.

The stabilization of the tidal estuaries along the central coast of Vietnam is one of the most urgent priority tasks to minimize the potential risks of natural disasters, especially floods and storms in the low-lying coastal plain, and to promote safe and stable conditions for socio-economic development in the region. Therefore, the results from the present study will support the development of a coastal zone management strategy for tidal inlets along the central coast of Vietnam.

Author Contributions: N.Q.D.A. performed most of the data analysis and numerical simulation works. H.T. and N.T.V. designed and supervised the present work. H.S.T. and T.T.T. performed the literature review and contributed to the interpretation of the results. N.X.T. wrote the first draft of manuscript and prepared the figures. All authors have read and agreed to the published version of the manuscript.

Funding: This study was supported by JSPS (Japan Society for the Promotion of Science) RONPAKU Program (ID No. R11808), and the bilateral program between Vietnam and Japan, entitled "Investigation of countermeasures to the overall stabilization the Truong Giang river, Nui Thanh District in order to satisfy the requirement the economics of sustainable developments in the study area and neighbored" (code: HNQT/SPĐP/16.19).

Acknowledgments: The authors would like to express their sincere gratitude to the financial support from the RONPAKU Program and the Bilateral Project.

Conflicts of Interest: The authors declare no conflict of interest.

\section{References}

1. Pradhan, U.; Mishra, P.; Mohanty, P.K.; Behera, B. Formation, growth and variability of sand spit at Rushikulya River Mouth, South Odisha Coast, India. In Proceedings of the 8th International Conference on Asian and Pacific Coasts (APAC), Chennai, India, 7-10 September 2015; Volume 116, pp. 963-970.

2. Allard, J.; Bertin, X.; Chaumillon, E.; Pouget, F. Sand spit rhythmic development: A potential record of wave climate variations? Arçay Spit, western coast of France. Mar. Geol. 2008, 253, 107-131.

3. Tribe, H.M. The Geomorphology of Farewell Spit and Its Sensitivity to Sea-level Rise. Master's Thesis, School of Geography, Environment and Earth Sciences, Victoria University of Wellington, Wellington, New Zealand, June 2008.

4. Stancheva, M.; Ratas, U.; Orviku, K.; Palazov, A.; Rivis, R.; Kont, A.; Peychev, V.; Tõnisson, H.; Stanchev, H. Sand dune destruction due to increased human impacts along the Bulgarian Black Sea and Estonian Baltic Sea Coasts. J. Coast. Res. 2011, 64, 6.

5. Aubrey, D.G.; Gaines, A.G. Rapid formation and degradation of barrier spits in areas with low rates of littoral drift. Mar. Geol. 1982, 49, 257-277. [CrossRef]

6. Cayocca, F. Long-term morphological modelling of a tidal inlet: The Arcachon Basin, France. Coast. Eng. 2001, 42, 115-142. [CrossRef]

7. McNinch, J.E.; Brodie, K.L.; Slocum, R.K. Radar Inlet Observing System (RIOS): Continuous remote sensing of waves, currents, and bathymetry at tidal inlets. Oceans 2012, 1, 14-19.

8. Sutherland, W.; Pullin, A.; Dolman, P.; Knight, T. The need for evidence based conservation. Trends Ecol. Evol. 2004, 19, 305-308. [CrossRef]

9. van Rijn, L.C.; Walstra, D.J.R.; Grasmeijer, B.; Sutherland, J.; Pan, S.; Sierra, J.P. The predictability of cross-shore bed evolution of sandy beaches at the time scale of storms and seasons using process-based profile models. Coast. Eng. 2003, 47, 295-327. [CrossRef]

10. Ridderinkhof, W.; de Swart, H.E.; van der Vegt, M.; Hoekstra, P. Modeling the growth and migration of sandy shoals on ebb-tidal deltas. J. Geophys. Res. Earth Surf. 2016, 121, 1351-1372.

11. Tung, T.T.; Walstra, D.R.; van de Graaff, J.; Stive, M.J.F. Morphological modeling of tidal inlet migration and closure. J. Coast. Res. 2009, SI56, 1080-1084. 
12. Tinh, N.X.; Thanh, T.M.; Tanaka, H.; Viet, N.T.; Dien, D.C.; Mitobe, Y. Numerical investigation of seasonal variation of depth of closure and shoreline change. Intl. J. Sed. Res. 2020, in press.

13. Benveniste, J.; Cazenave, A.; Vignudelli, S.; Fenoglio-Marc, L.; Shah, R.; Almar, R.; Andersen, O.; Birol, F.; Bonnefond, P.; Bouffard, J.; et al. Requirements for a coastal hazards observing system. Front. Mar. Sci. J. 2019, 6, 348.

14. Rogowski, P.; de Paolo, T.; Terrill, E.; McNinch, J. X-band radar mapping of morphological changes at a dynamic coastal inlet. J. Geophys. Res. Earth Surf. 2018, 123, 3034-3054. [CrossRef]

15. Honegger, D.A.; Haller, M.C.; Holman, R.A. High-resolution bathymetry estimates via X-band marine radar: 2. Effects of currents at tidal inlets. Coast. Eng. 2020, 156, 103626.

16. Duc Anh, N.Q.; Tanaka, H.; Tinh, N.X.; Viet, N.T. Sand spit morphological evolution at tidal inlets by using satellite images analysis: Two case studies in Vietnam. J. Sci. Tech. Civil. Eng. 2020, 14, 17-31.

17. Duc Anh, N.Q.; Duy, D.V.; Tanaka, H.; Viet, N.T. Elongation of sand spit at the Loc An river mouth, Southern Vietnam. J. JSCE Ser.B3 (Ocean Eng.) 2018, 74, I_695-I_700. [CrossRef]

18. Besset, M.; Anthony, E.J.; Brunier, G.; Dussouillez, P. Shoreline change of the Mekong River delta along the southern part of the South China Sea coast using satellite image analysis (1973-2014). Géomorph. Relief Processus Environ. 2016, 22, 137-146. [CrossRef]

19. Hung, N.M.; Larson, M. Coastline and river mouth evolution in the central part of the Red River Delta. In Coastal Disasters and Climate Change in Vietnam-Engineering and Planning Perspectives; Thao, N.D., Takagi, H., Esteban, M., Eds.; Elsevier Inc.: Amsterdam, The Netherlands, 2014; pp. 43-79.

20. Duy, D.V.; Tanaka, H.; Mitobe, Y.; Duc Anh, N.Q.; Viet, N.T. Sand spit elongation and sediment balance at Cua Lo inlet in Central Vietnam. J. Coast. Res. 2018, 81, 32-39.

21. Teodoro, A.C.; Pais-Barbosa, J.; Gonçalves, H.; Veloso-Gomes, F.; Taveira-Pinto, F. Extraction of Cabedelo sand spit area (Douro estuary) from satellite images through image processing techniques. J. Coast. Res. 2011, 64, 1740-1744.

22. Avinash, K.; Deepika, B.; Jayappa, K.S. Evolution of spit morphology: A case study using a remote sensing and statistical based approach. J. Coast. Cons. 2013, 17, 327-337. [CrossRef]

23. Dien, D.C.; Hung, N.M. Calibration and verification of a storm wave model in the coastal zones of the East Sea. In Proceedings of the 8th National Conference on Fluid Mechanics, Hanoi, Vietnam, 26-28 July 2006; Volume 8, pp. 25-35.

24. Goda, Y. Examination of the influence of several factors on longshore current computation with random waves. Coast. Eng. 2006, 53, 157-170. [CrossRef]

25. Tung, T.T. Morphodynamics of Seasonal Closed Coastal Inlets at the Central Coast of Vietnam. Ph.D. Thesis, Delft University of Technology, Delft, The Netherlands, 2011; 166p.

26. General Bathymetric Chart of the Oceans (GEBCO). GEBCO_2014 Grid, Version 20141103. Br. Oceanogr. Data Cent., Liverpool, U.K. 2014. Available online: http://www.gebco.net (accessed on 1 June 2019).

27. Anders, F.J. Accuracy of shoreline change rates as determined from maps and aerial photographs. Shore Beach 1991, 11, 17-26.

28. Goshasby, A.A. Theory and Applications of Image Registration; John Wiley \& Sons: Hoboken, NJ, USA, 2017; 520p.

29. Moore, L.J. Shoreline mapping techniques. J. Coast. Res. 2000, 16, 111-124.

30. Pradjoko, E.; Tanaka, H. Aerial photograph of Sendai coast for shoreline behavior analysis. In Proceedings of the 32nd Conference on Coastal Engineering, Shanghai, China, 30 June-5 July 2010; Volume 1.

31. Tanaka, H.; Takahashi, A.; Takahashi, F. Complete closure at the Nanakita River mouth in 1995. In Proceedings of the 25th International Conference on Coastal Engineering, Orlando, FL, USA, 2-6 September 1996; Volume 25, pp. 4545-4556.

32. Kraus, N.C. Analytical Model of Spit Evolution at Inlets. In Proceedings of the Coastal Sediment, ASCE, Long Island, NY, USA, 21-23 June 1999; pp. 1739-1754.

33. Larson, M.; Wikramanayake, N.; Hanson, H.; Ranasinghe, R. Seasonal closure of Chilaw Inlet, Sri Lanka: Physical processes and mathematical modeling. In Proceedings of the Coastal Dynamics, Tokyo, Japan, 7-11 September 2009; CD-ROM, Paper No. 97.

34. Duong, T.M.; Ranasinghe, R.; Luijendijk, A.; Waltsra, D.J.R.; Roelvink, D. Assessing climate change impacts on the stability of small tidal inlets-Part 1: Data poor environments. Mar. Geol. 2017, 390, 331-346. [CrossRef] 
35. Duong, T.M.; Ranasinghe, R.; Thatcher, M.; Mahanama, S.; Zheng, B.W.; Dissanayake, P.K.; Hemer, M.; Luijendijk, A.; Bamunawala, J.; Roelvink, D. Assessing climate change impacts on the stability of small tidal inlets: Part 2-Data rich environments. Mar. Geol. 2018, 395, 65-81. [CrossRef]

36. Reniers, A.J.H.M.; Roelvink, J.A.; Thornton, E.B. Morphodynamic modeling of an embayed beach under wave group forcing. J. Geophys. Res. 2004, 109, C01030. [CrossRef]

37. Van Rijn, L.C. Unified view of sediment transport by currents and waves. I: Initiation of motion, bed roughness and bed-load transport. J. Hydraul. Eng. 2007, 133, 649-667.

38. Van Rijn, L.C. Unified view of sediment transport by currents and waves. II: Suspended transport. J. Hydraul. Eng. ASCE 2007, 133, 668-689.

39. Tanaka, H.; Shuto, N. Hydraulic characteristics measured at the mouth of Same River in Japan. In Proceedings of the 5th Conference on Ocean Engineering, Hualien, Taiwan, 30 September-1 October 1981; pp. 377-395.

40. Tanaka, H.; Srivihok, P. Impact of Port Construction on Coastal and River Mouth Morphology-A Case Study at Sendai Port; Tsinghua University Press: Beijing, China, 2004; pp. 406-415.

41. Hung, N.M. Coastal and Estuarine Evolution in Vietnam; Vietnam Academy of Science and Technology (VAST): Ho Chi Minh City, Vietnam, 2010; 379p.

42. Palalane, J.; Larson, M.; Hanson, H. Analytical model of sand spit evolution. In Proceedings of the 34th International Conference on Coastal Engineering, Seoul, Korea, 15-20 June 2014.

43. Hoan, L.X.; Hanson, H.; Larson, M.; Kato, S. A mathematical model of spit growth and barrier elongation: Application to Fire Island Inlet (USA) and Badreveln Spit (Sweden). J. Estua. Coast. Shelf Sci. 2011, 93, 468-477. [CrossRef]

44. Dennis, K.C.; Niang-Diop, I.; Nicholls, R.J. Sea-level rise and Senegal: Potential impacts and consequences. J. Coast. Res. 1995, 14, 243-261.

(C) 2020 by the authors. Licensee MDPI, Basel, Switzerland. This article is an open access article distributed under the terms and conditions of the Creative Commons Attribution (CC BY) license (http://creativecommons.org/licenses/by/4.0/). 